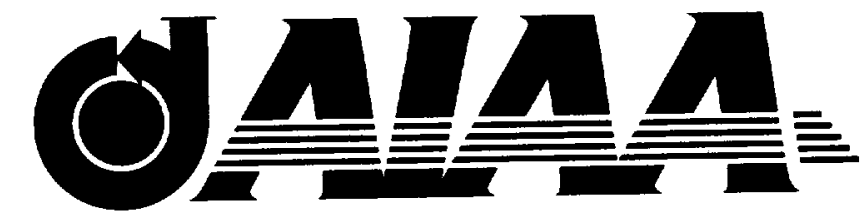

AIAA-2002-0418

Investigation of Reynolds Number Effects on a Generic Fighter Configuration in the National Transonic Facility (Invited)

W. G. Tomek, R. M. Hall, R. A. Wahls, J. M. Luckring, and L. R. Owens

NASA Langley Research Center

Hampton, Virginia

40th AIAA Aerospace Sciences Meeting \& Exhibit 14-17 January 2002

Reno, Nevada 


\title{
INVESTIGATION OF REYNOLDS NUMBER EFFECTS ON A GENERIC FIGHTER CONFIGURATION IN THE NATIONAL TRANSONIC FACILITY
}

\author{
W. G. Tomek ${ }^{1}$, R. M. Hall ${ }^{2}$, R. A. Wahls ${ }^{3}$, J. M. Luckring ${ }^{4}$, and L. R. Owens ${ }^{5}$ \\ Aerodynamics, Aerothermodynamics, and Acoustics Competency \\ NASA Langley Research Center \\ Hampton, Virginia
}

\begin{abstract}
A wind tunnel test of a generic fighter configuration was tested in the National Transonic Facility through a cooperative agreement between NASA Langley Research Center and McDonnell Douglas. The primary purpose of the test was to assess Reynolds number scale effects on a thin-wing, fighter-type configuration up to full-scale flight conditions (that is, Reynolds numbers of the order of 60 million). The test included longitudinal and lateral/directional studies at subsonic and transonic conditions across a range of Reynolds numbers from that available in conventional wind tunnels to flight conditions.

Results are presented for three Mach numbers $(0.6,0.8$, and 0.9$)$ and three configurations: 1) Fuselage / Wing, 2) Fuselage / Wing / Centerline Vertical Tail / Horizontal Tail, and 3) Fuselage / Wing / Trailing-Edge Extension / Twin Vertical Tails. Reynolds number effects on the longitudinal aerodynamic characteristics are presented herein.
\end{abstract}

\footnotetext{
${ }^{1}$ Aerospace Engineer, Research Facilities Branch, Member, AIAA

${ }^{2}$ Aerospace Engineer, Configuration Aerodynamics Branch, Associate Fellow, AIAA

${ }^{3}$ Assistant Branch Head, Configuration Aerodynamic Branch, Associate Fellow, AIAA

${ }^{4}$ Aerospace Engineer, Configuration Aerodynamics Branch, Associate Fellow, AIAA

${ }^{5}$ Aerospace Engineer, Flow Physics and Control Branch, Senior Member, AlAA

Copyright $\odot 2002$ by the American Institute of Aeronautics and Astronautics, Inc. No copyright is asserted in the United States under Title 17, U. S. Code. The U. S. Government has a royalty-free license to exercise all rights under the copyright claimed herein for Governmental Purposes. All other rights are reserved by the copyright owner.
}

\section{INTRODUCTION}

Simulation of flight at full-scale Reynolds numbers is now available through the use of cryogenic wind tunnels, such as the National Transonic Facility (NTF) at the NASA Langley Research Center. Some of the initial models tested in this facility were those built to study the Reynolds number effects on transport aircraft. These models were composed of U.S. aircraft industry designed and fabricated wings mounted to a NASA supplied generic fuselage, denoted as Pathfinder I (refs. 1 and 2). A similar need was identified for studying fighter aircraft concepts using a generic, area-ruled fuselage, which could accommodate a variety of wing planforms. NASA has denoted the fuselage for the configuration as Pathfinder II. Further general discussion of the Pathfinder II family of models can be found in references $1-3$.

The objectives of this wind tunnel investigation, utilizing the Pathfinder II fuselage with a McDonnell Douglas defined thin, fightertype wing, were to study the effects of Reynolds number on a fighter-type configuration through model component build-up and with stability and control device deployment (ref. 4). The test was conducted to provide a database of Reynolds number effects, up to full scale, which could be used to determine Reynolds number correlation trends, provide data for assessment of computational fluid dynamics (CFD) methods including turbulence modeling, and validate design and analysis methods.

This paper presents results from a single wind tunnel test, conducted from November - December 1995, focused on the Reynolds number sensitivities of longitudinal aerodynamic characteristics at subsonic and transonic conditions for three distinct configurations. The three major configurations 
tested were 1) a standard Fuselage / Wing (FW) configuration, 2) a Fuselage / Wing / Centerline Vertical Tail / Horizontal Tail (FWV1H) configuration, and 3) a Fuselage / Wing / Trailing-Edge Extension / Twin Vertical Tail (FWTV2) configuration.

\section{TERMS, ABBREVIATIONS, \& ACRONYMS}

\begin{tabular}{|c|c|}
\hline AF & Axial force \\
\hline AR & Aspect ratio \\
\hline$B L$ & Butt line \\
\hline Cl95 & $95 \%$ confidence interval \\
\hline c & Local chord length \\
\hline $\mathrm{C}_{\mathrm{D}}$ & Drag coefficient \\
\hline $\mathrm{C}_{\mathrm{L}}$ & Lift coefficient \\
\hline$C_{M}$ & $\begin{array}{l}\text { Pitching-moment coefficient } \\
\text { referenced to } 0.42 \mathrm{mac}\end{array}$ \\
\hline CP & Pressure coefficient \\
\hline CR & Root chord \\
\hline CT & Tip chord \\
\hline$E$ & Modulus of elasticity \\
\hline FW & Fuselage / Wing configuration \\
\hline FWV1H & $\begin{array}{l}\text { Fuselage / Wing / Centerline } \\
\text { Vertical Tail / Horizontal Tail } \\
\text { configuration }\end{array}$ \\
\hline FWVT2 & $\begin{array}{l}\text { Fuselage / Wing / Trailing-Edge } \\
\text { Extension / Twin Vertical Tail } \\
\text { configuration }\end{array}$ \\
\hline LaRC & Langley Research Center \\
\hline LE & Leading edge \\
\hline M & Mach number \\
\hline $\operatorname{mac}$ & Mean aerodynamic chord \\
\hline MS & Model station \\
\hline NF & Normal force \\
\hline NTF & National Transonic Facility \\
\hline PM & Pitching moment \\
\hline$P_{\mathrm{T}}$ & Total pressure \\
\hline Q & Dynamic pressure \\
\hline Rn & Reynolds number based on mac \\
\hline $\mathrm{RM}$ & Rolling moment \\
\hline SF & Side force \\
\hline Sref & Reference area \\
\hline $\mathrm{T}_{T}$ & Total temperature \\
\hline TE & Trailing edge \\
\hline TEX & Trailing-edge extension \\
\hline YM & Yawing moment \\
\hline$\alpha$ & Angle of attack \\
\hline$\eta$ & $\begin{array}{l}\text { Non-dimensional semispan } \\
\text { station }\end{array}$ \\
\hline
\end{tabular}

\section{EXPERIMENTAL APPROACH \\ Facility Description}

The NTF is a unique national facility (fig.

1) that enables testing of aircraft configurations at conditions ranging from subsonic to low supersonic speeds at Reynolds numbers up to full-scale flight values, depending on the aircraft type and size. The facility (fig. 2) is a fan-driven, closed-circuit, continuous-flow, pressurized wind tunnel capable of operating in either dry air at warm temperatures or nitrogen from warm to cryogenic temperatures. The test section is 8.2 $\mathrm{ft}$ by $8.2 \mathrm{ft}$ in cross section and $25 \mathrm{ft}$ in length. The test section floor and ceiling are slotted (6 percent open), and the sidewalls are solid. Freestream turbulence is damped by four screens and a 15:1 contraction ratio from the settling chamber to the test section. Fan noise effects are minimized by an acoustic treatment both upstream and downstream of the fan. The NTF is capable of an absolute pressure range from $15 \mathrm{psi}$ to $125 \mathrm{psi}$, a temperature range from $-260^{\circ} \mathrm{F}$ to $130^{\circ} \mathrm{F}$, a Mach number range from 0.2 to 1.2 , and a maximum Reynolds number of $146 \times 10^{6}$ per $\mathrm{ft}$ at Mach 1 . Further facility details can be found in reference 5 .

\section{Model Description}

The Pathfinder II configuration with the McDonnell Douglas wing is a generic model of a general research configuration. The model, shown in figure 3 , has the capability for testing numerous aerodynamic concepts including: two segment leading-edge flaps, trailing-edge flaps and ailerons, a trailing-edge extension (TEX) with a trailing-edge flap, and a wing tiperon. Only the TEX, un-flapped configuration was tested. The three configurations tested for this investigation are sketched in figure 4 . Figure $5 a$ shows a planform drawing of the model with pertinent reference geometry denoted. The model has a delta wing with an aspect ratio of 1.946 , a span of 20.802 inches, and a mean aerodynamic chord of 13.434 inches. The wing has a leading-edge sweep of 65 degrees with a trailing-edge sweep on the outboard panel of 35 degrees. The airfoil section is a NACA 65A004 at the root and a NACA $65 A 005$ at the tip with a linear thickness distribution from root to tip. Figure $5 \mathrm{~b}$ details the geometry of the respective empennage components. The reference area for the model is 1.544 square feet. 
The model was designed and constructed specifically for testing in the cryogenic, pressurized conditions of the NTF where dynamic pressures up to approximately 2300 psf were required for this investigation. The model was mounted in the NTF test section on a straight sting. The sting mounted to a stub sting which in turn mounted to the facility arc sector resulting in a model angle of attack range for the test from -2 to 18 degrees. Pertinent model geometry as compared to the NTF test section geometry is shown in table 1 . The model was relatively small in comparison to typical NTF transport or high-speed research models.

The model was instrumented with 43 pressure ports on the wing upper surface and 18 on the wing lower surface. Additionally, there were 22 upper surface pressure ports along the fuselage centerline (aft of nose) and slightly offcenter on the aft fuselage. Limited pressure data is presented herein.

\section{Instrumentation}

Aerodynamic force and moment data were obtained with an internal, unheated, sixcomponent strain gauge balance. Design loads for the NTF $104 \mathrm{~B}$ balance were: $N F=3400 \mathrm{lbs}$, $A F=300 \mathrm{lbs}, P M=10,000$ in-lbs, $R M=5000$ in-lbs, $Y M=5000$ in-lbs, and $S F=1000 \mathrm{lbs}$. The quoted accuracy from the calibration of the balance was less than or equal to $0.23 \%$ of full-scale load for each balance component.

An internal, heated, single-axis, onboard accelerometer package was used to measure the model angle of attack. The accelerometer package had a quoted accuracy, under smooth operating tunnel conditions, of \pm 0.01 degrees (ref. 6 ).

Model pressure measurements were obtained using two 48-port, 30-psid, onboard, heated, electronically scanned pressure (ESP) transducers with a quoted accuracy of $\pm 0.2 \%$ of full-scale pressure range. The body cavity pressure was measured at two locations inside the fuselage cavity with a heated, 2.5-psid ESP module located in the facility arc sector.

The primary measured flow variables included both the total and static pressures and the total temperature. Mach number, Reynolds number, and dynamic pressure were calculated from these measured parameters. A complete description of these measurements and subsequent calculations is given in reference 7 .

\section{Data Reduction and Corrections}

Information on the various instrumentation devices, the data acquisition and control computers, and the data reduction algorithms for the different measurement systems is provided in reference 7 . Standard balance, angle-of-attack, and tunnel parameter corrections have been applied. Note that the use of unheated balances in the cryogenic environment requires additional attention towards temperature compensation. The temperature compensation methods are designed to correct balance output due to thermal loads. Body cavity pressure corrections were applied based on the measurements described previously. The angle of attack was corrected for flow angularity (upflow) by measurement of both upright and inverted model force data for a given configuration and flow condition. Wall and model support interference effects have not been accounted for in the data; wall effects are assumed minimal due to the model size relative to test section (see table 1).

\section{Test Conditions}

The test program was set-up to evaluate the effect of full-scale Reynolds numbers and produce an aerodynamic database applicable to thin-wing, fighter-type configurations. The NTF allows testing across a wide range of Reynolds numbers from that available in conventional wind tunnels to near flight conditions at subsonic and transonic Mach numbers. The Reynolds numbers chosen for the test matched full-scale conditions at selected altitudes of 20,000, 30,000 , and 40,000 feet, representative of operational fighter aircraft altitudes. Tests of the Pathfinder II model spanned Reynolds numbers from 5 million to 60.9 million at Mach numbers $0.6,0.8$, and 0.9 . Representative test points for Mach 0.9 are shown in figure 6. Data were obtained at several total temperature conditions requiring both air and nitrogen mode operations. Data were obtained over an angle-of-attack range from -2 to 18 degrees.

The initial configuration was tested to acquire force and model pressure data simultaneously. In an attempt to relieve any possible fouling or any thermally induced loads from the pressure tubing bridging the balance, 
the pressure tubes were cut and removed after a set of pressure data was acquired on the initial Fuselage / Wing configuration. The configuration was then re-tested for only force and moment data. Hence, there is force and moment data for all three configurations available, but only pressure data available for the Fuselage / Wing configuration.

\section{Boundary-Laver Transition}

A basic strategy used at the NTF includes testing at high Reynolds number conditions with free transition. The high Reynolds number test condition typically corresponds to a design flight condition. To anchor the NTF data to low Reynolds number data obtained in a conventional wind tunnel, the NTF model is usually tested at a matching low Reynolds number condition with the boundarylayer tripping (forced transition) strategy used in a conventional wind tunnel. However, for this investigation, no tripping of the boundary layer was utilized for any test condition (Mach, Reynolds number) since the test was focused on the high Reynolds number data evaluation. The impact of this decision will be discussed in succeeding sections.

\section{RESULTS \& DISCUSSION}

The purpose of this paper is to document the Reynolds number sensitivities of longitudinal aerodynamic characteristics for a generic fighter configuration at subsonic and transonic conditions. The three configurations investigated were a baseline Fuselage / Wing assembly (FW), a configuration with a centerline vertical tail and a horizontal tail $\left(F W_{1} 1 \mathrm{H}\right)$, and a twin vertical tail configuration with a trailing-edge extension (FWTV2). Figure 7 shows representative data for the three configurations at a representative Mach number of 0.6 at a medium Reynolds number of 22 million and is provided to indicate the basic aerodynamic characteristics of the configurations. The data, as acquired at varying Reynolds numbers, included the combined effects of aeroelastic deformation and Reynolds number effects because the conditions at which the data were acquired were at different dynamic pressure levels in general; further discussion will address the aeroelastic effects.

\section{Repeatability}

The short-term repeatability of the force and moment data from the Pathfinder II model was analyzed. Repeat runs were not conducted for every configuration or for all Mach numbers, but were scattered throughout the test program. The analysis for the available repeat runs was conducted using the methodology as described in reference 8 . The analysis consists of statistical determination of the mean value of the selected coefficients from repeated runs, a curve fit of the data using a $2^{\text {nd }}$ order polynomial, and a determination of the residual of the individual data points from the curve fit data. Confidence intervals are determined and are defined as the bounds about an estimated mean that encompasses the true mean value with a probability of $95 \%$ confidence.

A repeatability residual analysis is shown in figure 8 for the longitudinal coefficients at Mach 0.6 and a representative high Reynolds number condition. Table 2 is a summary of short-term repeatability of the longitudinal coefficients for the representative FW configuration. Repeatability was excellent for the longitudinal coefficients for the angles of attack where attached flow is dominant, but degrades somewhat for angles of attack greater than 4 degrees and for higher angles of attack where separated flow dominates. In general, there is good short-term repeatability for the longitudinal aerodynamic coefficients and is comparable to the quoted balance accuracy. Long-term repeatability or test-to-test repeatability data are not available to compare.

\section{Static Aeroelastic Effects}

The investigation of aerodynamic effects on a model in a variable-pressure facility such as the NTF should take into account the possible aeroelastic effects. These effects could mask the other aerodynamic effects, such as Reynolds number effects, which are being studied. Since the NTF is capable of controlling Mach number, dynamic pressure, and temperature independently, the desired test plan would be to test at comparable dynamic pressures, or more specifically, comparable dynamic pressures divided by modulus of elasticity (Q/E) values. However, based on limitations on the strength of the model material, tunnel capability limitations, or nitrogen usage rates, the test plan is normally compromised, 
and the data from the test, if required, are "normalized" to provide similar wing shape comparisons.

Data for this particular model were taken at two different dynamic pressure levels at the same Reynolds number ( $R n=22$ million). A representative example of dynamic pressure effects is shown in figure 9 for the FW configuration. Data are presented as a delta plot and compare the higher dynamic pressure run at the same Reynolds number as referenced to the lower dynamic pressure level.

Aeroelastic effects on the longitudinal aerodynamic coefficients were detectable, even for this low aspect ratio configuration, but were generally small. It was decided not to adjust data for these effects in the analysis for this report, though future analysis may include such adjustments. It is interesting to note, in figure 9 , the increase in lift at high dynamic pressure (and $Q / E)$ even at high lift conditions, implying a leading-edge-up wing twist not typically seen with other models. Though not shown, this trend was not consistent for all Mach numbers and may be indicative of changing center-ofpressure characteristics relative to the elastic axis of the wing. Wing twist photogrammetry measurements under load would have added to understanding of these effects, but the currently operational measurement system (ref. 9) was not available during this test.

\section{Reynolds Number Effects}

The effects of Reynolds numbers on this generic fighter configuration were analyzed for the three configurations and three different Mach numbers tested. Three distinct angles of attack were investigated to evaluate these effects for different flow states. These representative angles of attack were 1) $\alpha=0.5$ degrees, approximately minimum drag, 2) $\alpha=4.0$ degrees, a near design condition, and 3) $\alpha=$ 12.0 degrees, a separated flow condition. The highlights of this analysis are detailed below with key representative figures.

\section{Fuselage / Wing Configuration (FW)}

For the baseline FW configuration at a Mach number of 0.6 , near minimum drag ( $\alpha=$ 0.5 degrees), there appears to be an initial insensitivity to Reynolds number below 22 million, as shown in figure 10, and a trend of decreasing drag as Reynolds number increases above 22 million. Upon closer examination, the drag for the lower Reynolds numbers (5 million and 12 million) does not appear to be consistent with a general decrease in drag with increasing Reynolds number as seen from the expected theoretical fully turbulent drag result (anchored to the highest Reynolds number). The measured drag for this condition is considerably below the theoretical, fully turbulent drag. The likely cause for this result is the lack of fixed boundary layer transition at the lower Reynolds number conditions. For these conditions, it is expected that the boundary layer flow over the wing will be a combination of both laminar and turbulent flow. In fact, there can be a significant region of laminar flow for these conditions. This would likely explain the apparent drag deficit measured at this condition. To verify these results, a repeat of the baseline configuration with the boundary layer tripped in the NTF would be needed. There is no observable effect on either lift or pitching moment at this particular angle of attack as a function of Reynolds number.

The general Reynolds number trends for the longitudinal aerodynamic coefficients near minimum drag ( $\alpha=0.5$ degrees) at Mach $=0.8$ and 0.9 (figures 11,12 ) for the FW configuration are consistent with the trends at Mach $=0.6$. The drag coefficients at the lowest Reynolds numbers (5 and 12 million) again show a decreased magnitude as compared to the fully turbulent theory. The pitching moment and lift at these Mach numbers are also insensitive across the Reynolds number range. There appear to be no compressibility effects on the trends with Reynolds number for characteristics of this configuration at the minimum drag condition.

Figures 13 and 14 show Reynolds number trends for the $\mathrm{FW}$ configuration at a near design, primarily attached flow condition ( $\alpha$ $=4.0$ degrees) and a highly separated flow condition ( $\alpha=12.0$ degrees) at Mach 0.90. The expected effect of decreasing drag with an increase in Reynolds number was observed, and, though theory is not shown, there are less indications of significant laminar flow at the low Reynolds numbers. Lift is insensitive to Reynolds number at these flow conditions, like at the minimum drag condition, but the pitching moments show an increasing sensitivity to Reynolds number changes. At an angle of attack of 4.0 degrees (near the design condition) 
at Mach 0.90, the pitching moment (figure 13) shows an increase (nose-up) as the Reynolds number increases beyond 12 million. This characteristic is also observed at an angle of attack of 12.0 degrees (figure 14), but the insensitivity below 12 million is gone and the rate of increased pitching moment with Reynolds number is higher. Note that there is a potentially significant aeroelastic effect at this separated flow condition at a constant Reynolds number of 22 million. At this Reynolds number and angle of attack, drag decreases with increasing dynamic pressure with a corresponding decrease in lift. This would be representative of a small wing twist deflection downward producing a decreased local angle of attack. The aeroelastic effect is also apparent in the pitching moment where an increased nose-up moment accompanies the increase in dynamic pressure; this result is consistent with a lift decrease associated with a leading-edge down wing twist at the tip with constant body angle of attack.

Another way of understanding the flow characteristics as Reynolds number changes is with the analysis of the model surface pressure data. Although there were limited pressure data acquired during the test, some interesting results were obtained. For example, leading-edge pressures for one spanwise station $(\eta=0.22)$ are shown in figure 15 for the FW configuration. This figure highlights pressures for three Reynolds numbers as a function of angle of attack at a Mach number of 0.9. Two trends can be seen. First, the leading edge pressures are becoming increasingly more negative until the angle of attack reaches about 4 degrees. This is consistent with attached flow below that angle of attack. Second, the effect of increasing Reynolds number is to reduce the level of suction for angles of attack greater than 4 degrees. This reduction is consistent with the expectation that higher Reynolds numbers will delay separation over the leading edge. Delayed separation will result in less vorticity being generated and, therefore, weaker suction in the separated region. This observation, however, does not help to explain the pitch-up character with Reynolds number noted above in figures 13 and 14 . This discrepancy will be addressed in future studies.

\section{Fuselage / Wing / Centerline Vertical Tail/ Horizontal Tail Configuration (FWV1H)}

The effects of Reynolds number on the FWV $1 \mathrm{H}$ configuration at Mach 0.9 and 4 degrees angle of attack are shown in figure 16. Drag and lift trends with Reynolds number for this configuration are very similar to the FW configuration, though absolute levels change due to the addition of model components. With increasing Reynolds number, the drag shows a downward trend; this trend holds at other angles of attack and for Mach 0.6 and 0.8. The lift is insensitive to Reynolds number for this configuration for all Mach numbers at 4 degrees angle of attack.

The pitching moment trends for the FWV1H configuration are different than the FW configuration. Figure 16 shows a decreasing (more nose-down) moment with increasing Reynolds number below 22 million; above 22 million, pitching moment is insensitive to changes in Reynolds number. This different behavior, compared to the FW configuration, is likely due to the addition of the tail components and flow field interactions between the wing and tail. This configuration warrants further study to understand the details relevant to this behavior.

\section{Fuselage / Wing / Trailing-Edge Extension /} Twin Vertical Tail Configuration (FWTV2)

The effects of Reynolds number on the FWTV2 configuration at Mach 0.9 and 4 degrees angle of attack are shown in figure 17. Drag and lift trends with Reynolds number for this configuration are very similar to the $\mathrm{FW}$ and FWV1H configurations, though absolute levels change due to the different empennage components. With increasing Reynolds number, the drag shows a downward trend; this trend holds at other angles of attack and for Mach 0.6 and 0.8. The lift is insensitive to Reynolds number for this configuration for all Mach numbers at 4 degrees angle of attack.

The pitching moment trends for the FWTV2 configuration are similar to the FWV1H configuration, and thus different than the $\mathrm{FW}$ configuration. Figure 17 shows a decreasing (more nose-down) moment with increasing Reynolds number below 22 million; above 22 million, pitching moment is insensitive to changes in Reynolds number at this angle of attack. As with the $\mathrm{FWV} 1 \mathrm{H}$ configuration, this different behavior, compared to the FW 
configuration, is likely due to the addition of the tail components and flow field interactions between the wing and tail. This configuration also warrants further study to understand the details relevant to this behavior.

The neutral point characteristics of the three configurations at Mach 0.9 are shown in figure 18 as a function of Reynolds number. The neutral point is defined as the location where the pitching moment coefficient is independent of the angle of attack. It is also representative of where the center of pressure (center of lift) is located relative to the mean aerodynamic chord. The pitching moment data were referenced to $0.416 \mathrm{mac}$. Figure 18 shows, for the three configurations, the respective movement of the center of pressure for angles of attack previously analyzed $(0.5,4$, and 12 degrees). At a representative Mach number of 0.9 , the baseline $F W$ configuration shows a forward movement of the center of pressure (about $4 \%$ ) for the two attached flow conditions ( $\alpha=0.5$ and $\alpha=4.0$ degrees). This movement of the neutral point indicates an increase in aft separation and decrease in aft loading with an increase in Reynolds number. For the separated flow condition ( $\alpha=12$ degrees), the center of pressure moves forward approximately $15 \%$. In general, for separated flow conditions, the neutral point is not expected to maintain its position. However, this Reynolds number effect, in addition to the effect of the angle of attack, could have significant implications on the stability and control power required for the vehicle. The FWTV2 configuration shows a lesser, but still significant, effect at the higher angle of attack; center of pressure movement at the attached flow conditions is similar to the FW. The FWV1H configuration significantly reduces the movement of the neutral point with Reynolds number for the separated flow condition, but shows similar attached flow characteristics.

\section{CONCLUDING REMARKS}

A wind tunnel test with a generic fightertype model was executed in the National Transonic Facility at NASA LaRC across a wide range of Reynolds numbers from that available in conventional wind tunnels to flight conditions at subsonic and transonic Mach numbers. Results were presented which focus on the Reynolds sensitivities of longitudinal characteristics at Mach $0.6,0.8$, and 0.90 for three unique configurations. General conclusions are summarized as follows:

1. Static aeroelastic effects on the longitudinal aerodynamic coefficients were detectable, but were generally small. The effects were larger at the higher angles of attack.

2. Drag trends for the lowest Reynolds numbers ( 5 and 12 million) tested were differed from theoretical fully turbulent skin friction estimates. The likely cause for this result is significant regions of laminar flow due to the lack of fixed boundary layer transition at the lower Reynolds number conditions.

3. Lift was generally insensitive to Reynolds number for the configurations and conditions tested.

4. Reynolds number effects are larger at angles of attack where separated flow dominates, particularly the pitching moment characteristics. The presence of tail components altered the pitching moments trends with Reynolds number.

\section{ACKNOWLEDGEMENTS}

The authors would like to thank the Boeing Company, formerly McDonnell Douglas, for their support in this wind tunnel investigation. We would like to specifically thank Mr. Wayne L. Ely (retired) of McDonnell Douglas for his important contributions before, during, and after this investigation. Without his effort, this test would not have been accomplished. Also, we would like to acknowledge the representatives of the National Transonic Facility for their support during the testing and subsequent data processing. 
AIAA-2002-0418

\section{REFERENCES}

1. Campbell, J.F.: "The National Transonic Facility - A Research Perspective," AIAA Paper 84-2150, August 1984.

2. Wahls, R.A.: "The National Transonic Facility: A Research Retrospective," AIAA Paper 01-0754, January 2001.

3. Luckring, J.M.: "An Overview of National Transonic Facility Investigations for High Performance Military Aerodynamics," AIAA Paper 01-0906, January 2001.

4. Ely, W.L.: "Summary Report for the Pathfinder II Full-Scale Reynolds Number National Transonic Facilty Wind Tunnel Test - Test 77," Report Number MDA 96P0049, October 1996.

5. Fuller, D.E.: "Guide for Users of the National Transonic Facility," NASA TM-83124, 1981.

6. Finley, T.D. and Tcheng, P.: "Model Attitude Measurements at NASA Langley Research Center," AIAA Paper 92-0763, 1992.

7. Foster, J.M. and Adcock, J.B.: "User's Guide for the National Transonic Facility Research Data System," NASA TM-110242, April 1996.

8. Wahls, R.A., Adcock, J.B., Witkowski, D.P., and Wright, F.L..: "A Longitudinal Aerodynamic Data Repeatability Study for a Commercial Transport Model in the National Transonic Facility," NASA TP-3522, August 1995.

9. Burner, A.W., Wahls, R.A., and Goad, W.K.: "Wing Twist Measurements at the National Transonic Facility," NASA TM-110229, February 1996.

\begin{tabular}{|r|c|}
\hline ref. area / NTF cross sectional area & 0.023 \\
\hline model span / NTF width & 0.211 \\
\hline solid blockage ratio, $\alpha=0$ deg & 0.0039 \\
\hline
\end{tabular}

Table 1. Model size relative to the NTF test section.

\begin{tabular}{|c|c|c|c|c|c|}
\hline Mach & Rn, 10 & q, psf & $\Delta \mathrm{C}_{\mathrm{D}}$ & $\Delta \mathrm{C}_{\mathrm{L}}$ & $\Delta \mathrm{C}_{\mathrm{M}}$ \\
\hline 0.6 & 5 & 590 & .00004 & .0003 & .00006 \\
\hline 0.6 & 56 & 1608 & .00020 & .0020 & .00010 \\
\hline 0.9 & 60.5 & 2309 & .00015 & .0015 & .00030 \\
\hline
\end{tabular}

Table 2. Repeatability data for FW configuration (95\% confidence interval evaluated over entire alpha range). 


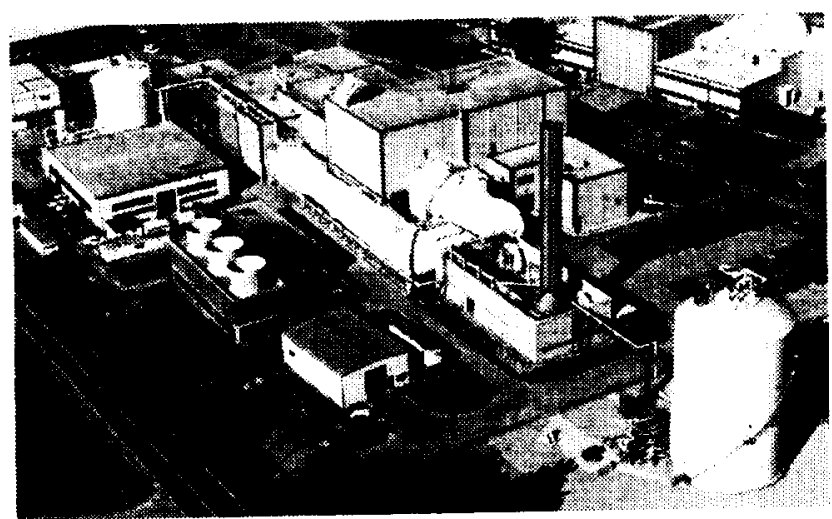

Figure 1. External view of the NTF.

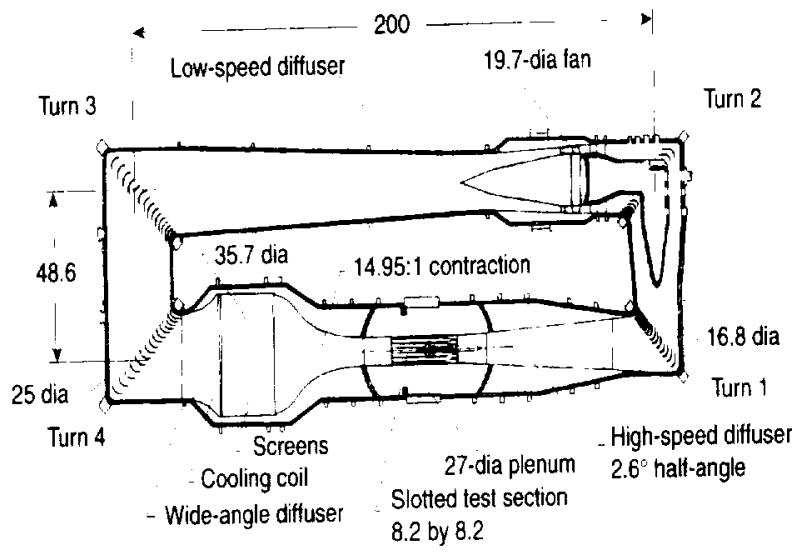

Figure 2. NTF circuit diagram (dimensions in $\mathrm{ft}$ ).

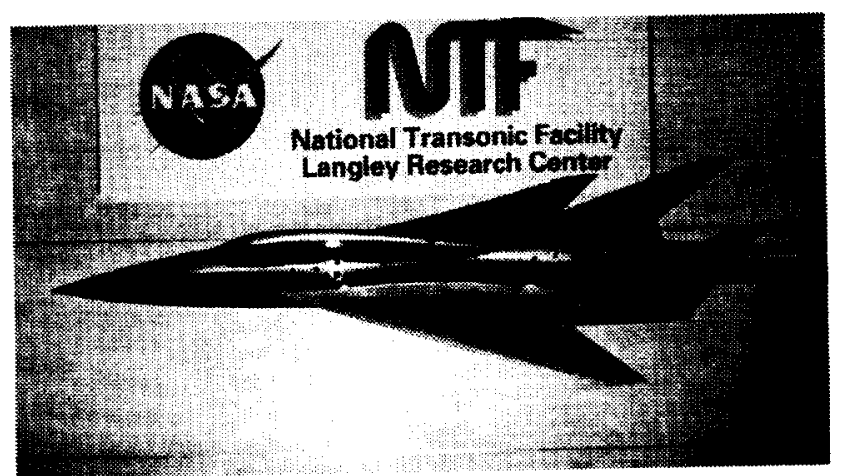

Figure 3. Pathfinder II model with McDonnell Douglas defined wing in the NTF.
Fuselage/Wing

(FW)

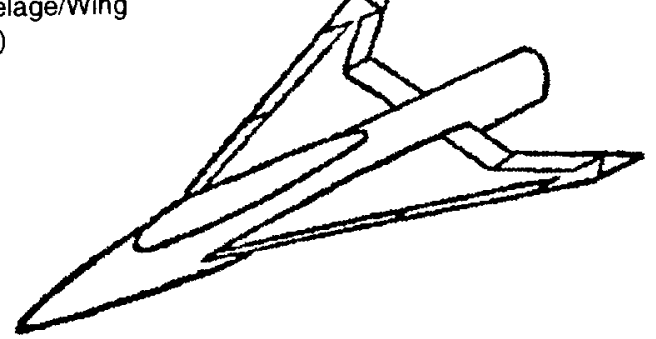

Fuselage/Wing/Vertical Tail/Horizontal (FWV1H)

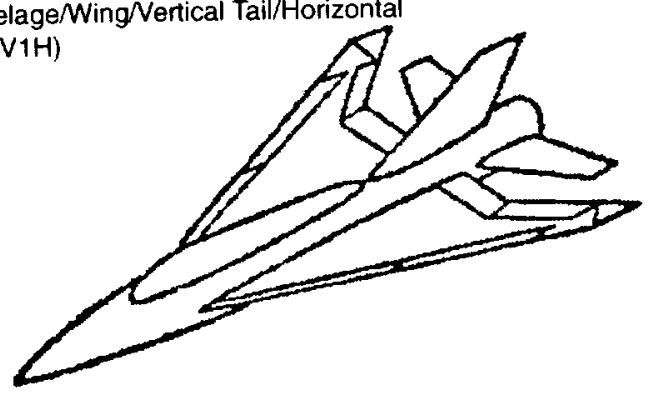

Fuselage/Wing/Trailing Edge Extension/Twin Vertical Tails (FWTV2)

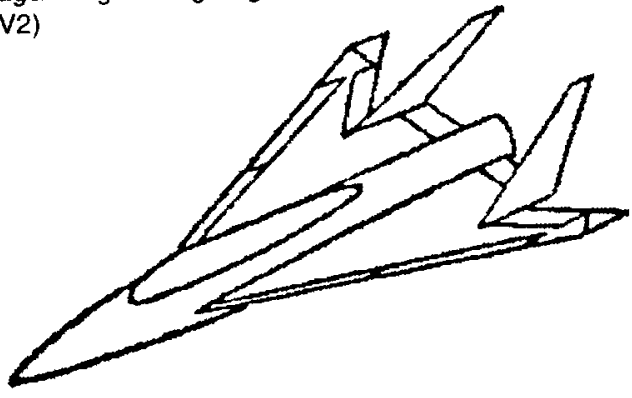

Figure 4. Pathfinder II model with McDonnell Douglas wing/empennage configurations. 


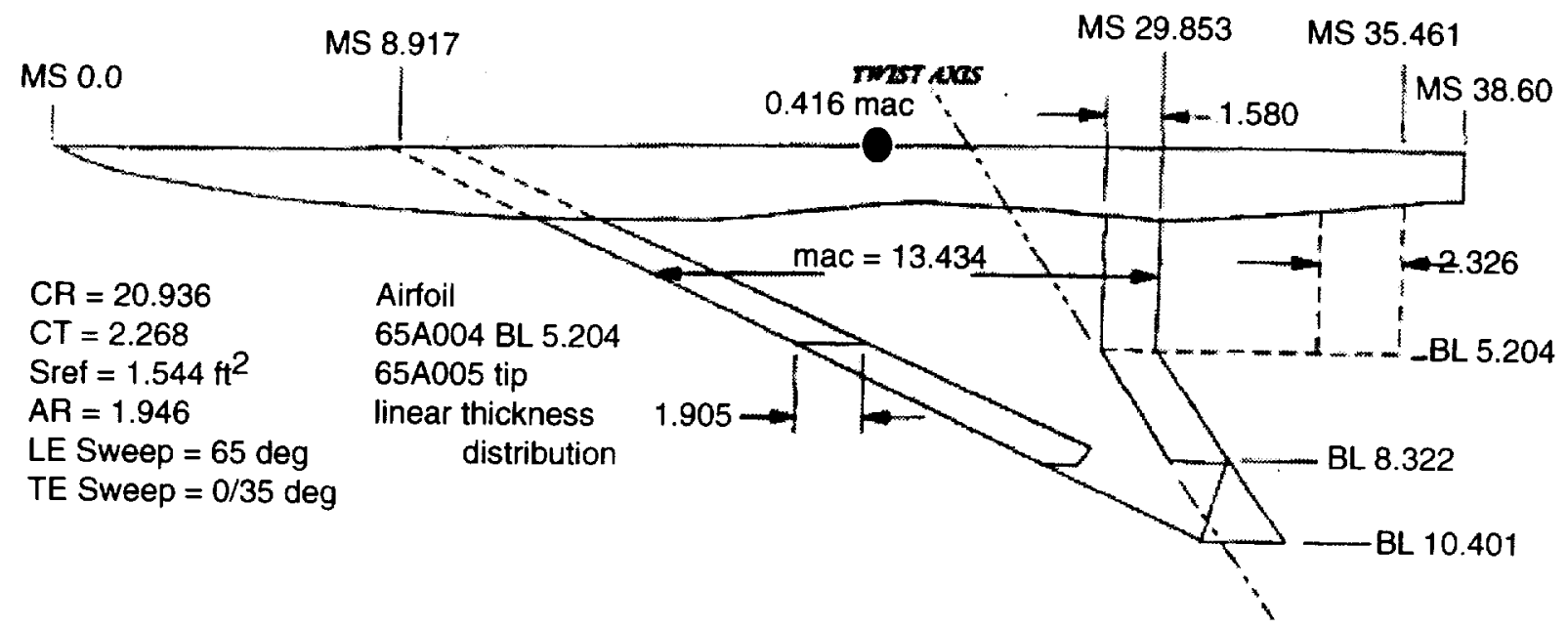

a) fuselage, wing, and trailing-edge extension (dimensions in inches).

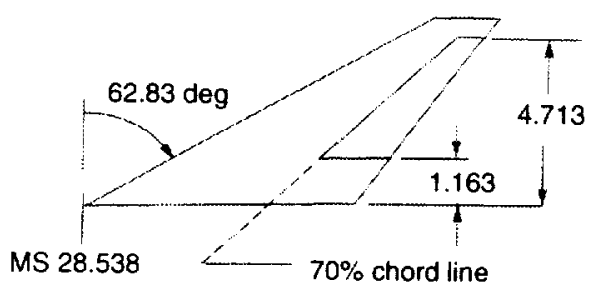

Twin Vertical Tail

Airfoil $-65 A 005$, modified LE radius $=0.159 \% \mathrm{C}$

$\mathrm{CR}=7.923$

$\mathrm{CT}=1.827$

Height $=5.236$

Cant $=15 \mathrm{deg}$ inboard

Horizontal Tail

Airfoil - $5.5 \%$ thick symmetric

Single Vertical Tail

Airfoil - $4 \%$ thick symmetric

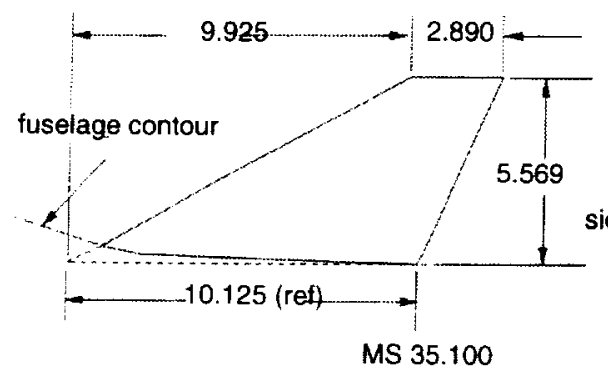

side of fuseläḡè

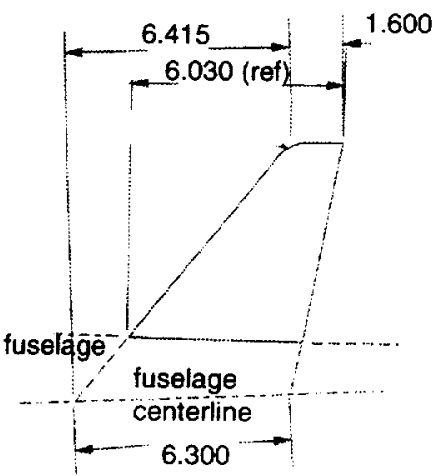

MS 29.800

b) empennage components (dimensions in inches).

Figure 5. Model geometry (dimensions in inches). 


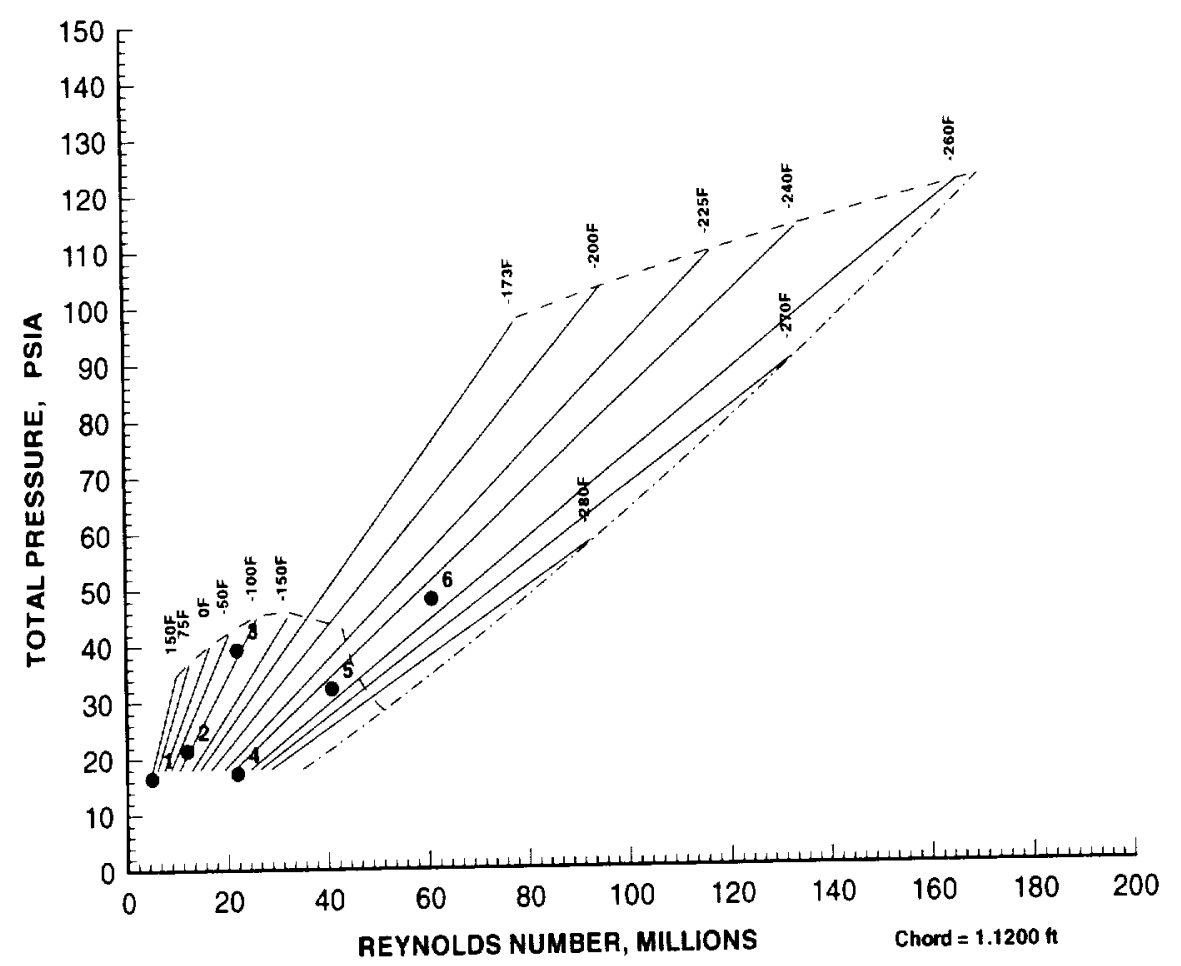

Figure 6 . Test conditions, $M=0.90$.

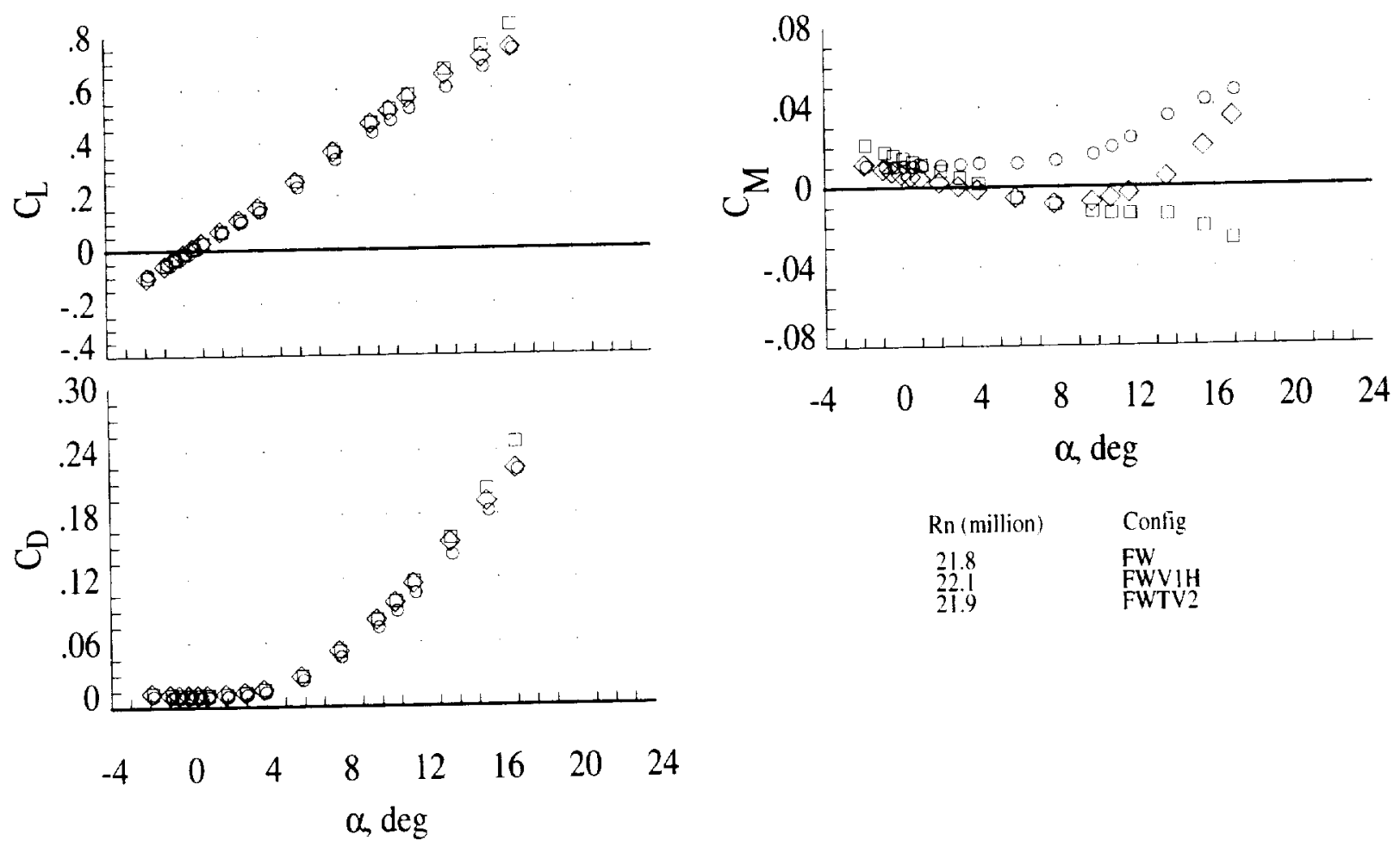

Figure 7. Representative longitudinal force and moment data, $M=0.6$. 
AIAA-2002-0418
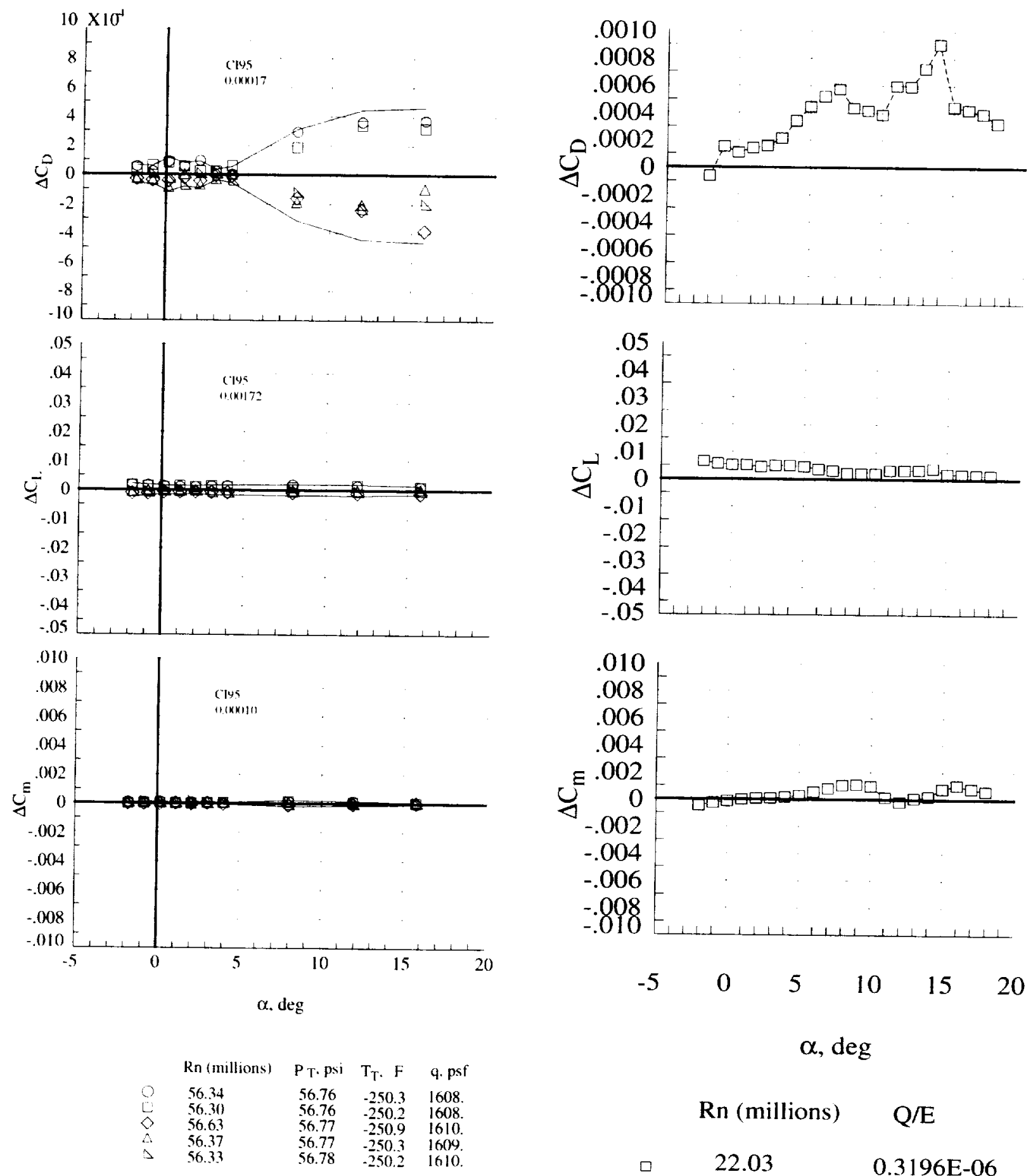

Figure 8. Short-term repeatability, FW configuration, $M=0.60$.

$$
\begin{aligned}
& \alpha, \operatorname{deg} \\
& \text { Rn (millions) Q/E } \\
& \text { ㅁ } 22.03 \quad 0.3196 \mathrm{E}-06
\end{aligned}
$$

Figure 9. Incremental static aeroelastic effects on longitudinal coefficients, FW configuration, referenced to $\mathrm{Q} / \mathrm{E}=0.1592 \mathrm{E}-06, \mathrm{M}=0.60$. 


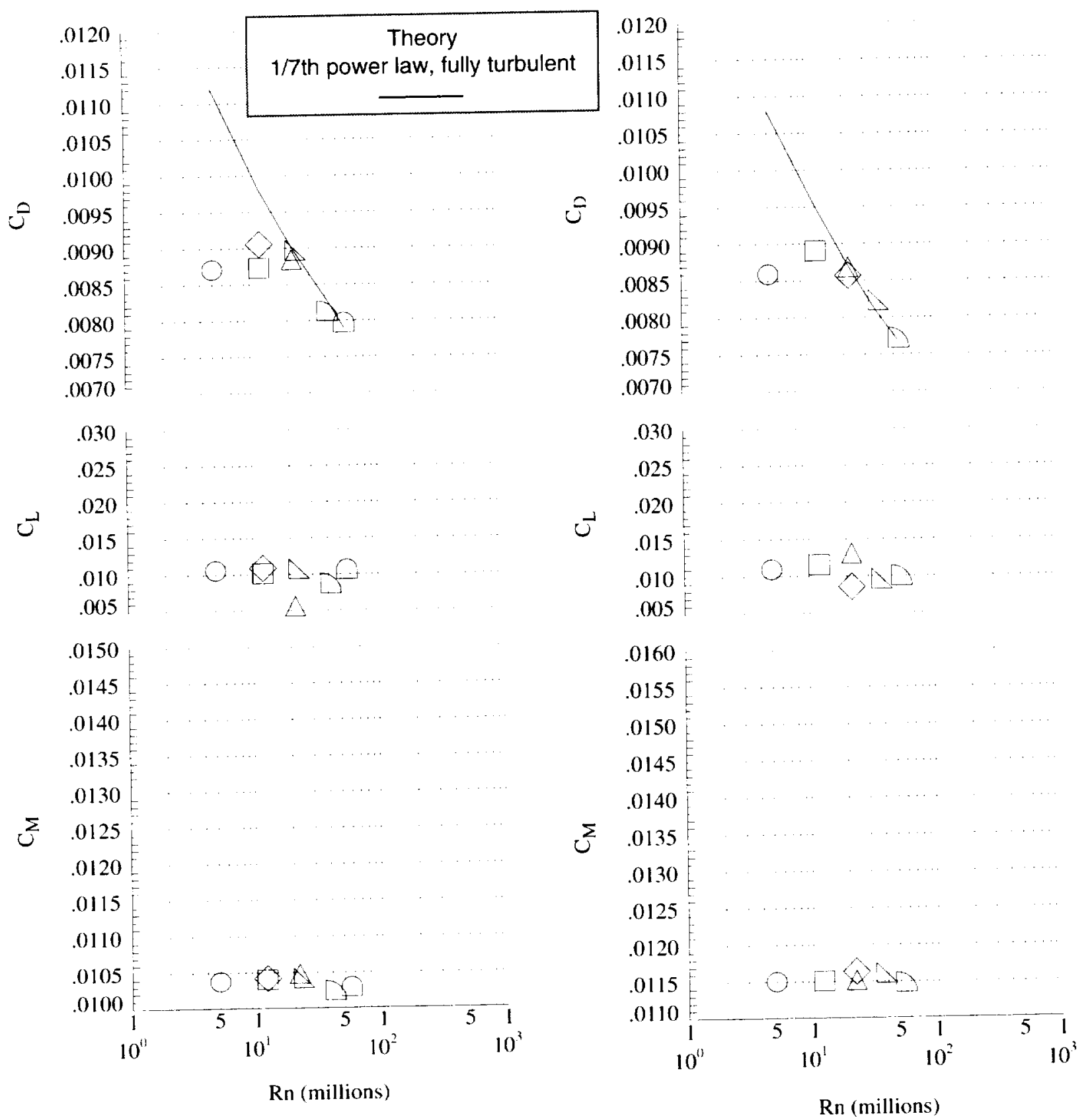

$\begin{array}{lllll}\alpha, \text { deg } & \text { Rn (millions) } & \text { q. psf } & \mathbf{P}_{\mathrm{T}}, \mathrm{psi} & \mathbf{T}_{\mathrm{T}}, \mathrm{lF} \\ 0.5 & 5.01 & 592 . & 20.70 & 119.9 \\ 0.5 & 11.96 & 1415 . & 49.60 & 120.9 \\ 0.5 & 12.00 & 674 . & 23.69 & -124.7 \\ 0.5 & 21.80 & 626 . & 22.09 & -249.1 \\ 0.5 & 22.03 & 1239 . & 43.38 & -125.4 \\ 0.5 & 40.71 & 1160 . & 40.86 & -250.6 \\ 0.5 & 56.31 & 1608 . & 56.76 & -250.2\end{array}$

Figure 10. Longitudinal coefficient trends with Reynolds number, $F W$ configuration, near minimum drag, $M=0.6$.

$\begin{array}{lllll}\alpha . \text { deg } & \text { Rn (millions) } & \text { q. psf } & \text { P }_{\mathrm{T}} \text {. psi } & \mathrm{T}_{\mathrm{T}}, \mathrm{F} \\ 0.5 & 4.99 & 738 . & 17.41 & 120.7 \\ 0.5 & 12.05 & 834 . & 19.71 & -126.2 \\ 0.5 & 22.01 & 777 . & 18.41 & -250.0 \\ 0.5 & 22.04 & 1534 . & 36.20 & -125.5 \\ 0.5 & 36.23 & 1278 . & 30.27 & -250.1 \\ 0.5 & 53.82 & 1910 . & 45.22 & -249.3\end{array}$

Figure 11. Longitudinal coefficient trends withReynolds number, $F W$, configuration, near minimum drag, $M=0.8$. 


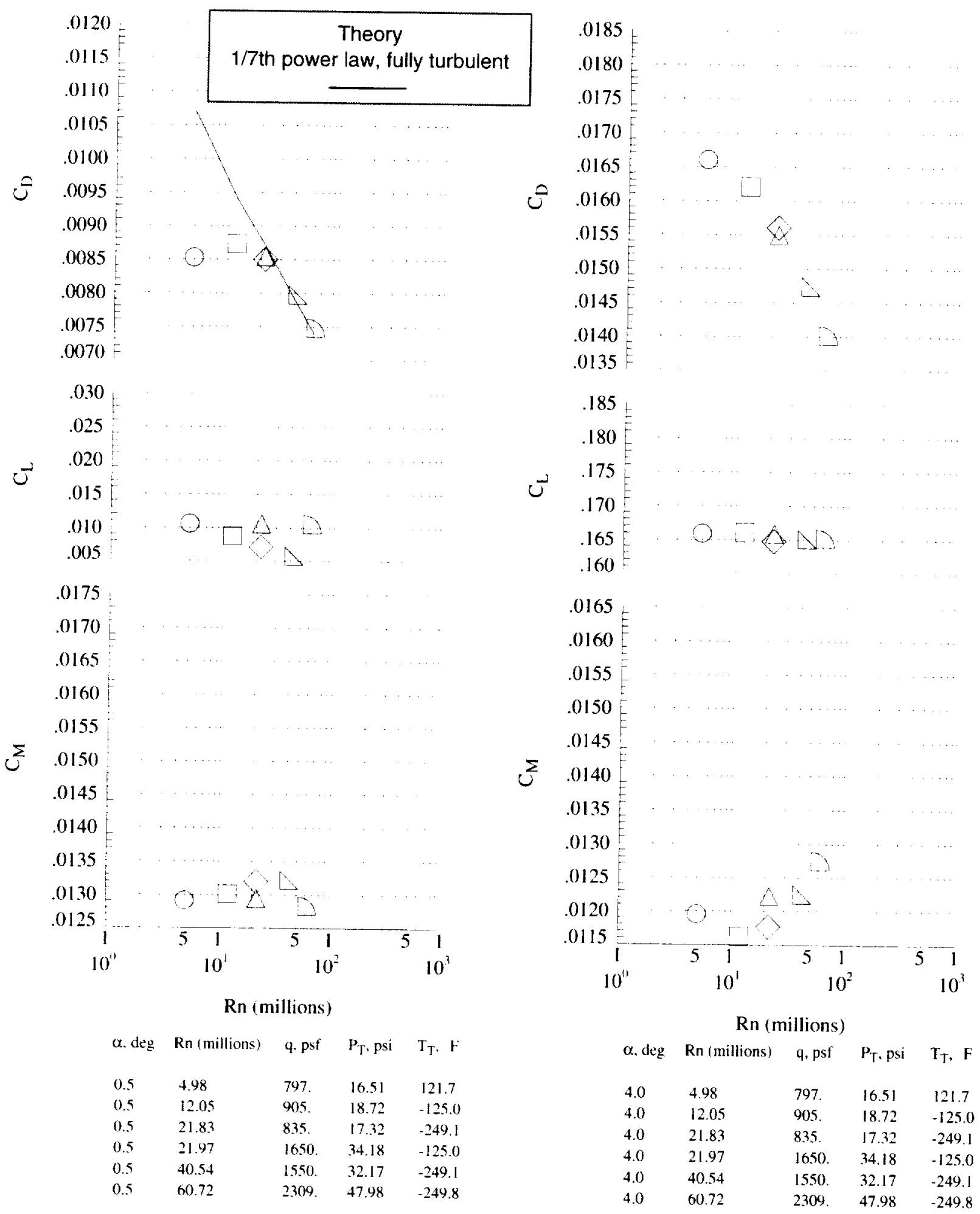

Figure 12. Longitudinal coefficient trends with Reynolds number, FW configuration, near minimum drag, $M=0.9$

Figure 13. Longitudinal coefficient trends with Reynolds number, FW configuration, near design condition, $M=0.9$. 


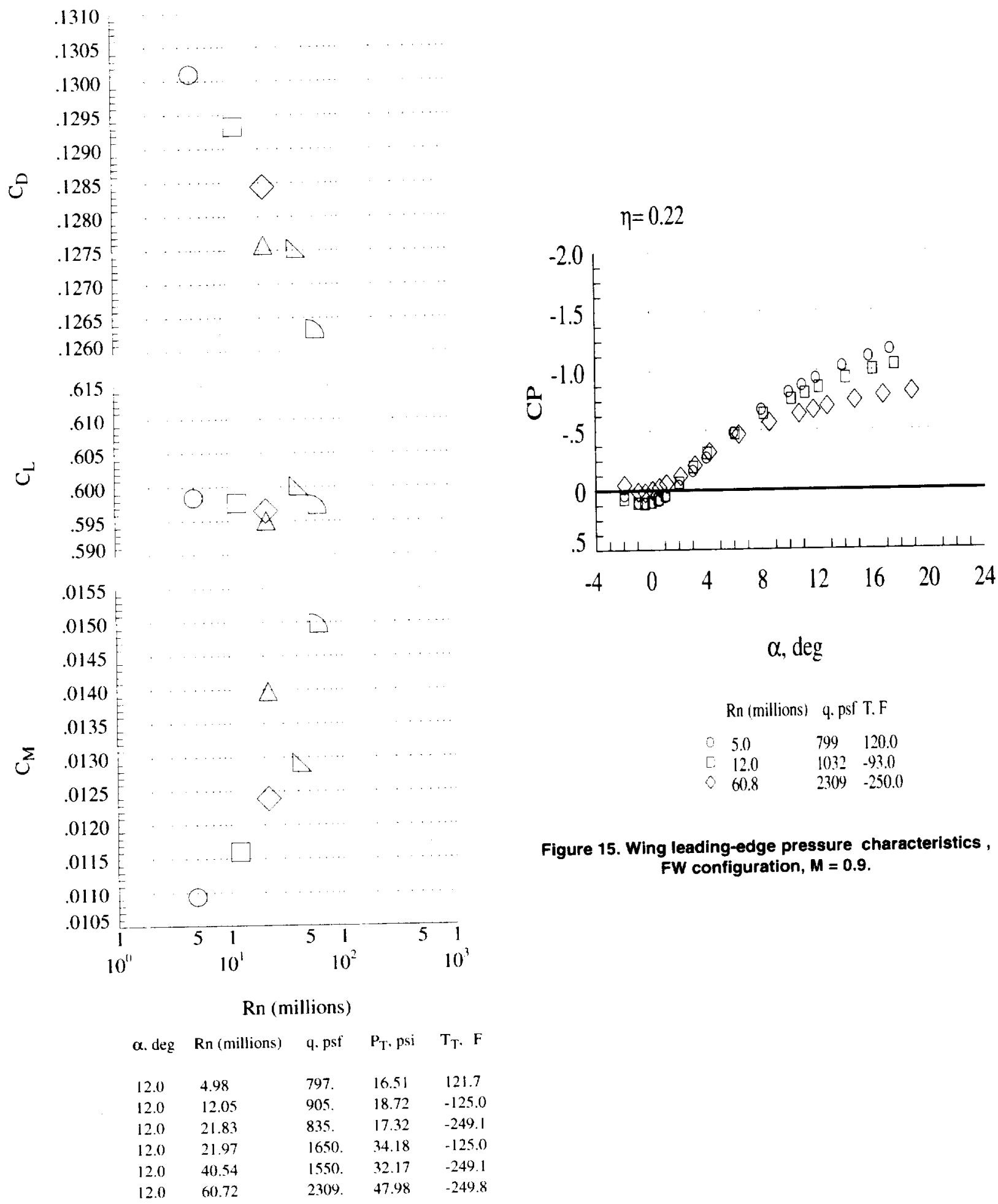

Figure 14. Longitudinal coefficient trends with Reynolds number, FW configuration, separated flow, $M=0.9$. 
AIAA-2002-0418
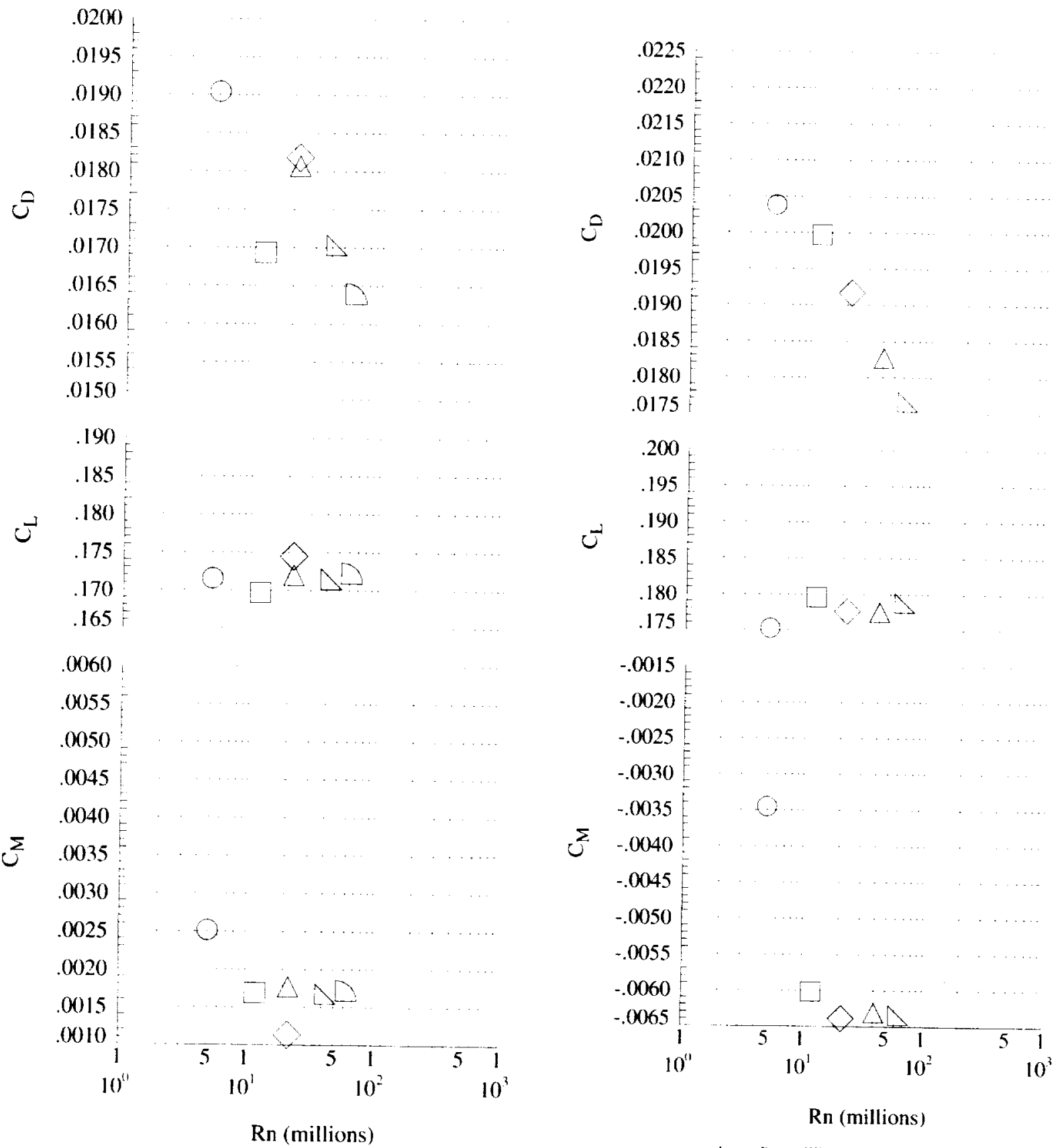

$\begin{array}{lllll}\alpha . \text { deg } & \text { Rn (millions) } & \text { q.psf } & P_{\mathrm{T}} . \mathrm{psi} & \mathrm{T}_{\mathrm{T}}, \mathrm{F} \\ 4.0 & 5.00 & 797 . & 16.51 & 119.6 \\ 4.0 & 12.05 & 904 . & 18.71 & -125.1 \\ 4.0 & 21.92 & 835 . & 17.32 & -249.7 \\ 4.0 & 22.01 & 1651 . & 34.18 & -125.4 \\ 4.0 & 40.64 & 1548 . & 32.18 & -249.5 \\ 4.0 & 60.75 & 2311 . & 48.03 & -249.7\end{array}$

\begin{tabular}{|c|c|c|c|c|}
\hline \multicolumn{5}{|c|}{ Rn (millions) } \\
\hline$\alpha \cdot$ deg & Rn (millions) & q. psf & $\mathrm{P}_{\mathrm{T}} \cdot \mathrm{psi}$ & $\mathrm{T}_{\mathrm{T} \cdot \mathrm{F}}$ \\
\hline 4.0 & 4.98 & 796. & 16.50 & 121.0 \\
\hline 4.0 & 12,03 & 903. & 18.72 & -124.9 \\
\hline 4.0 & 21.67 & 835. & 17.30 & -248.2 \\
\hline 4.0 & 40.53 & 1552. & 32.21 & -248.9 \\
\hline 4.0 & 60.76 & 2307 & 48.00 & -249.9 \\
\hline
\end{tabular}

Figure 17. Longitudinal coefficient trends with Reynolds number, FWTV2 configuration, near design, $M=0.9$.

Figure 16. Longitudinal coefficient trends with Reynolds number, FWV1H configuration, near design, $M=0.9$. 
FW

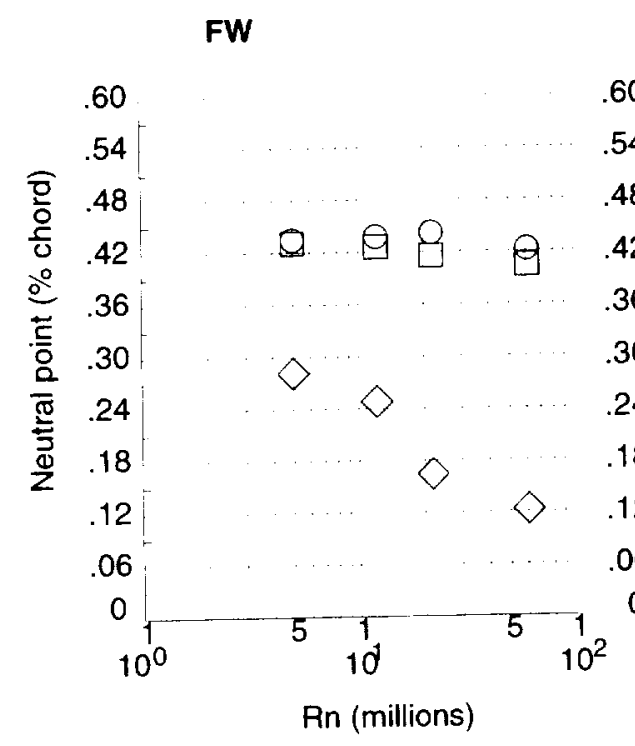

FWV1H

.60

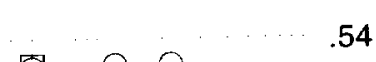

$8 \cdot \theta \theta \quad \theta \quad .48$

.48

.36

.30

.24

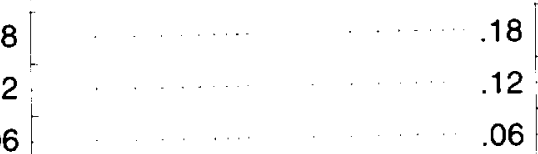

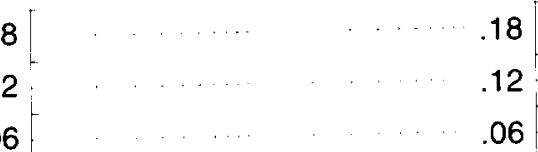

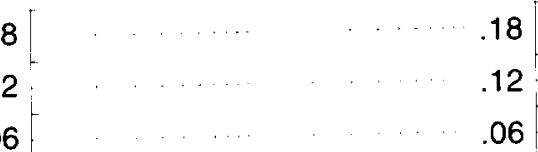

FWTV2

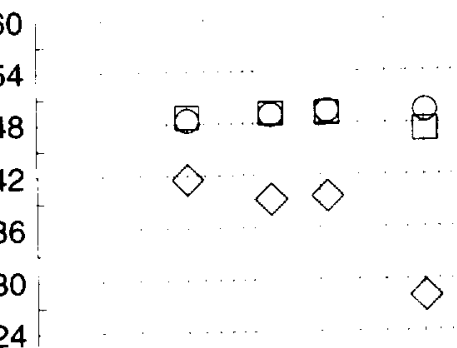

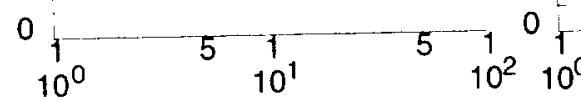

Rn (millions)

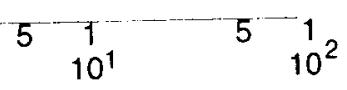

Rn (millions)

Mo $\propto$ deg

$\begin{array}{lll}\circ & 0.90 & 0.5 \\ \diamond & 0.90 & 4.0 \\ \diamond & 0.90 & 12.0\end{array}$

Figure 18. Variation of neutral point with Reynolds number, $M=0.9$ 


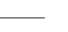



